\title{
Calculation of pulse voltage stabilizer
}

\author{
Dmitry Cheremukhin ${ }^{1, *}$ \\ ${ }^{1}$ Far Eastern Federal University, Russia, Vladivostok
}

\begin{abstract}
This scientific article is devoted to one of the priority issues in electronics, namely the implementation of the engineering task of designing a power source. In my case, according to the terms of reference, which includes: the main parameters of the network, efficiency, a structural electrical circuit of a switching power supply was developed. In the process, the main functional units (blocks) were calculated and the choice of radio components from which they were built on the basis of: current values, reverse voltage, gain, operating frequency and other parameters of diodes, transistors, integrated circuits, Zener diodes, operational amplifiers was justified. In the "Methods" section, calculations will be made for the device blocks: a network rectifier, a push-pull transformer converter, a pre-amplifier circuit with a transformer input, an error signal comparison and amplification circuit, a sawtooth voltage generator, and a secondary power source. The information presented in the text is recommended to a narrow circle of specialists, priority in the field of power electronics, as well as in the field of communication systems.
\end{abstract}

\section{Introduction}

Switching voltage stabilizer - a voltage regulator in which the regulating element is in the cutoff mode $\left(\mathrm{R}_{\max }\right)$ or under saturation $\left(\mathrm{R}_{\text {min }}\right)$, hence can be considered as the key $[1,121]$. Smooth change of voltage occurs due to the presence of integrating elements: the voltage rises as you accumulate them energy and decreases its impact in the load. This mode reduces energy loss and improves weight and overall dimensions, however, has its own characteristics.

Essential elements of a switching power supply are: integrator, which voltage can not change instantly, but gradually increases according to the accumulation of energy and then slowly drops as it returns to the load (for example a capacitor, to which included some non-zero resistance, which can be, for example, the internal resistance of the power source) and a device able to change the resistance to the passage of current from minimum to maximum and Vice versa.

\section{Methods}

This simulation was carried out at the Department of Electronics and Communications. During the calculations, the Mathcad program was used, as well as the development environment of electronic circuits Multisim.

\section{Materials}

Has been provided by the technical specification (requirements) regarding the network conditions for which it is planned to produce the product. Input the following:

Power supply voltage: $\mathrm{Ups}=36 \mathrm{~V}$; the Relative change in supply voltage: $\delta \mathrm{Ups}= \pm 20 \mathrm{~V}$; Frequency mains current: $F=400 \mathrm{~Hz}$; Type of mains supply: three phase with a "0" output star; Diagram of the network rectifier: three-phase half-wave; load Voltage: $\mathrm{U}$ load = $12 \mathrm{~V}$; load Current max: I $1 \max =5 \mathrm{~A}$; load Current min: $\mathrm{I} 1 \mathrm{~min}=1 \mathrm{~A}$; ambient Temperature: $\mathrm{t}=+50 \mathrm{C}$; ripple Factor: $\mathrm{Kr}=1.5 \%$; The switching frequency of the Converter: fs $=25 \mathrm{kHz}$; Diagram of converters: push-pull; efficiency: $\eta=92 \%$.

\subsection{The calculation of the network rectifier}

Depending on the number of phases supply rectification circuit may be a three-phase bridge, three phase halfwave, single-phase bridge.

In (Fig.1) shows a diagram of a network rectifier "three phase half-wave rectified".

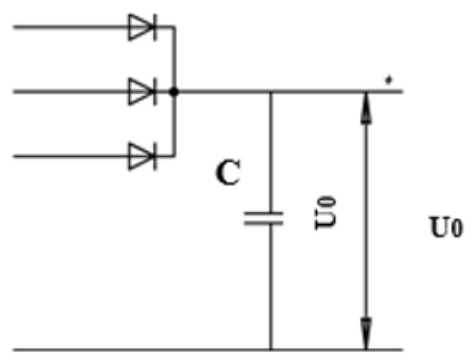

Fig. 1. Scheme of three-phase half-wave rectifier.

Calculate the main parameters:

\footnotetext{
* Corresponding author: dodgevipersrt15@ mail.ru
} 
The average value of the rectified voltage for threephase half-wave circuits:

$$
\mathrm{U}_{0 \text { rated }}=0.95 \mathrm{U}_{\mathrm{ps}} \sqrt{2}=0.95 \cdot 36 \cdot \sqrt{2}=47.9 \mathrm{~V}
$$

The maximum value of the rectified voltage:

$$
\mathrm{U}_{0 \max }=\mathrm{U}_{0 \text { rated }} \cdot\left(1+\delta_{\mathrm{U}_{p s}}\right)=47.9 \cdot(1+0.2)=57.46 \mathrm{~V}
$$

The minimum value of the rectified voltage:

$$
\mathrm{U}_{0 \min }=\mathrm{U}_{0} \cdot\left(1-\delta_{\mathrm{U}_{\mathrm{ps}}}\right)=47.9 \cdot(1-0.2)=43.08 \mathrm{~V}
$$

The capacitance value:

$$
\mathrm{C}_{1}=1.3 \frac{\mathrm{P}_{\text {load }}}{\eta}=1.3 \frac{\mathrm{I}_{\text {load } \max } \cdot \mathrm{U}_{\mathrm{H}}}{\eta}=1.3 \cdot \frac{5 \cdot 12}{0.92}=84.15 \mu \mathrm{F}
$$

Taken on a table e24: $\mathrm{C}_{1}=100 \mu F$.

The value of current-limiting (to limit charge current) resistance:

$$
\mathrm{R}_{0}=\frac{\mathrm{U}_{\text {stabil max }}}{\mathrm{I}_{\text {varib }}}=\frac{60}{6}=10 \mathrm{Ohm}
$$

Taken on a table e24: $R_{0}=12 \mathrm{Ohm}$.

For selecting the rectifier diode, the required values:

The average current through the valve:

$$
\begin{gathered}
\mathrm{I}_{1,2,3}=\frac{\mathrm{I}_{0}}{3}=\frac{0.313}{3}=0.104 \mathrm{~A} \\
\mathrm{P}_{0}=\mathrm{I}_{0}^{2} * U=0.9 \mathrm{~W} \\
\mathrm{I}_{0}=\frac{\mathrm{P}_{0}}{\mathrm{U}_{0 \text { min }}}=\frac{13}{43.08}=0.313 \mathrm{~A}
\end{gathered}
$$

The magnitude of the reverse voltage to the idle valve:

$$
\mathrm{U}_{\text {reverse }}=\mathrm{U}_{\mathrm{ps}} \sqrt{2} \sqrt{3}=36 \cdot \sqrt{2} \cdot \sqrt{3}=87.19 \mathrm{~V}
$$

According to the data selected diode KD209B with the following parameters:

Table 1. Parameters of the Diode KD209B.

\begin{tabular}{|c|c|}
\hline Diode & Ipr.cp, $_{\text {. A }}$ \\
\hline KD209B & 0.5 \\
\hline U rev., V & I variable, $\mathrm{A}$ \\
\hline 600 & 6 \\
\hline
\end{tabular}

\subsection{Calculation of transformer push-pull converter}

In this popular scheme (Figure 2), the performance is a combination of electric energy conversion and its regulation through pulse width modulation. Characteristic for them is the presence of a relatively strong smoothing LC filter [2, 63].

In half-bridge scheme of transformer push-pull converter, when the transistor VT1 is opened at time $\gamma$
$\mathrm{T} / 2$, and VT2 is closed, energy transfer occurs from capacitor $\mathrm{C} 1$ through a transformer $\mathrm{T}$ to the cumulative LC choke and the load [3,51]. At the same time, the capacitance $\mathrm{C} 2$ is charged through the circuit: +U0, U1 winding, the capacitance $\mathrm{C} 2$ and $-\mathrm{U} 0$. In the next half cycle the process repeats: the $\mathrm{S} 2$ is open, $\mathrm{C} 1$ is charged. During the pause, the filter capacitor $\mathrm{C}$ is discharged to the load through the diode VD5. Capacitance C1, C2 form a capacitive divider.

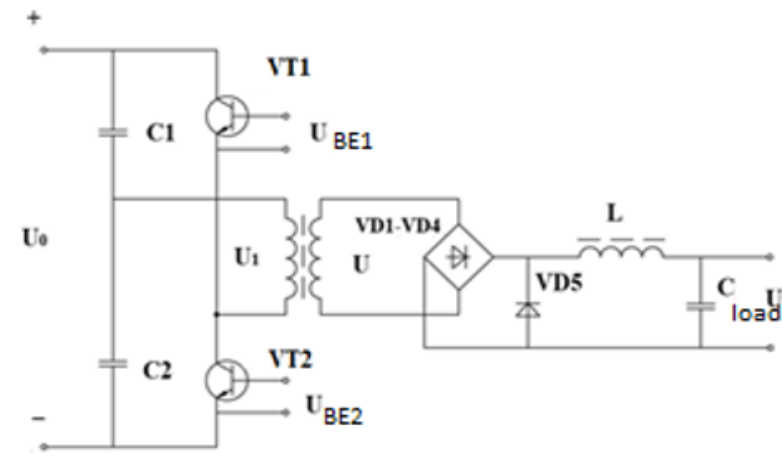

Fig. 2. Schematic diagram.

Capacity $C_{1}$ and $C_{2}$ form a capacitive divider:

$$
U_{1}=\frac{U_{0}}{2}=\frac{47.9}{2}=23.95 \mathrm{~V}
$$

The fill factor of the pulse: $\gamma_{\max }=0.7$

The output voltage of an RF rectifier:

$$
\begin{gathered}
\mathrm{U}_{2 \text { min }}^{\prime}=\frac{\mathrm{U}_{\text {load }}}{\gamma_{\text {max }}}=\frac{12}{0.7}=17.1 \mathrm{~V} \\
\mathrm{U}_{2 \text { rated }}^{\prime}=\frac{\mathrm{U}_{2 \min }^{\prime}}{\left(1-\delta \mathrm{U}_{\mathrm{ps} \max }\right)}=\frac{17.1}{(1-0.2)}=21.4 \mathrm{~V} \\
\mathrm{U}_{2 \text { max }}^{\prime}=\mathrm{U}_{2 \text { rated }}^{\prime} \cdot\left(1+\delta \mathrm{U}_{\mathrm{ps} \max }\right)=21.4 *(1+0.2)=25.6 \mathrm{~V} \\
\gamma_{\text {min }}=\frac{\mathrm{U}_{\text {load }}}{\mathrm{U}_{2 \text { max }}^{\prime}}=\frac{12}{25.6}=0.5
\end{gathered}
$$

The voltage at the secondary winding of the transformer:

$$
\mathrm{U}_{2}=\mathrm{U}_{2}^{\prime}+\mathrm{U}_{\mathrm{ddv}}=17.1+1=18.1 \mathrm{~V}
$$

where $\mathrm{U}_{\mathrm{ddv}}$ - forward drop voltage of the diodes an HF bridge.

The value of the output inductor:

$$
\mathrm{L}=(5 \div 10) \cdot \frac{\mathrm{R}_{\text {load }} \cdot\left(1-\gamma_{\text {min }}\right)}{2 \cdot \mathrm{f}_{\mathrm{s}}}=7 \cdot \frac{12 \cdot(1-0.5)}{2 \cdot 25 \cdot 10^{3}}=84 \mu \mathrm{H}
$$

Taken on a number e24: $L=100 \mu H$. Load resistance $\left(\mathrm{R}_{\text {load }}\right)$ :

$$
\mathrm{R}_{\text {load }}=\frac{\mathrm{U}_{\text {load }}}{\mathrm{I}_{\text {load min }}}=\frac{12}{1}=12 \mathrm{Ohm}
$$

Taken on a number e24: $R_{\text {load }}=12 \mathrm{Ohm}$. 
The maximum current of the inductor:

$$
\mathrm{I}_{L \max }=\mathrm{I}_{\text {load }}+\Delta \mathrm{i}_{1}=5+3.42=8.42 \mathrm{~A}
$$

Ripple current through the inductor:

$$
\Delta \mathrm{i}_{1}=\frac{\mathrm{U}_{2}^{\prime} \gamma_{\max }}{2 \cdot \mathrm{L} \cdot \mathrm{f}_{\mathrm{s}}}=\frac{17.1 \cdot 0.7}{2 \cdot 84 \cdot 10^{-6} \cdot 25 \cdot 10^{3}}=2.85 \mathrm{~A}
$$

The capacity of the smoothing filter:

When $\mathrm{K}_{\mathrm{r}}=2 \%$, get:

$\mathrm{C}_{\text {load }}=\frac{\left(1-\gamma_{\min }\right)}{8 \cdot \mathrm{L} \cdot \mathrm{f}_{\mathrm{s}}{ }_{\mathrm{s}} \cdot \mathrm{K}_{\mathrm{r}}}=\frac{(1-0.5)}{8 \cdot 84 \cdot 10^{-6} \cdot 25^{2} \cdot 10^{6} \cdot 0.02}=50 \mu \mathrm{F}$

Taken on a number e24: $C_{\text {load }}=50 \mu F$.

Average current of the diode VD5 and its voltage:

$$
\begin{gathered}
\mathrm{I}_{\mathrm{a} \text { VD5 }}=\mathrm{I}_{\mathrm{L} \max }\left(1-\gamma_{\min }\right)=8.42 *(1-0.5)=4.21 \mathrm{~A} \\
\mathrm{U}_{\text {rev VD5 }}=\mathrm{U}_{2 \max }^{\prime}=25.6 \mathrm{~V}
\end{gathered}
$$

The average value of the currents and reverse voltage for diodes HF bridge [4]:

$$
\begin{aligned}
& \mathrm{I}_{\mathrm{am}}=\frac{\mathrm{I}_{\mathrm{load}}}{2}=\frac{5}{2}=2.5 \mathrm{~A} \\
& \mathrm{U}_{\text {reverse }}=\mathrm{U}_{2 \text { max }}=19 \mathrm{~V}
\end{aligned}
$$

As the diode bridge is used KD213A with the following parameters:

Table 2. Parameters of the Diode bridge KD213A.

\begin{tabular}{|c|c|}
\hline Diode bridge & Idirect.average, $\mathrm{A}$ \\
\hline KD213A & 10 \\
\hline $\mathrm{U}_{\text {rev. }}, \mathrm{V}$ & I $_{\text {direct }}$ \\
\hline 200 & 100 \\
\hline $\mathrm{F}, \mathrm{kHz}$ & \multicolumn{1}{|}{} \\
\hline 100 &
\end{tabular}

The maximum current value $\mathrm{I}_{2}$ of the secondary winding:

$$
\mathrm{I}_{2}=\mathrm{I}_{\mathrm{L} \max }=8.42 \mathrm{~A}
$$

\begin{tabular}{|c|c|c|c|}
\hline Type & $\mathrm{H}_{21 \mathrm{e}}$ & $\begin{array}{c}\mathrm{U}_{\mathrm{BE}} . \\
\text { saturation, } \mathrm{V}\end{array}$ & \\
\hline KT812A & 30 & 2.2 & \\
\hline $\begin{array}{c}\mathrm{U}_{\mathrm{CE}} \\
\text { saturation, } \mathrm{V}\end{array}$ & $\mathrm{f}_{\text {cutoff }}, \mathrm{MHz}$ & $\mathrm{U}_{\mathrm{CEmax}}, \mathrm{V}$ & $\mathrm{I}_{\mathrm{CEmax}}, \mathrm{A}$ \\
\hline 1.35 & 6.5 & 400 & 8 \\
\hline
\end{tabular}

For half-bridge circuits:

The collector current $I_{\text {load max }}$ and the max value of $\mathrm{U}_{\mathrm{CE} \text { max }}$ to pick VT:

$$
\begin{aligned}
\mathrm{I}_{\mathrm{C} \max }=\frac{\mathrm{U}_{2} \cdot \mathrm{I}_{2}}{\mathrm{U}_{1} \cdot \eta} & =\frac{18.1 \cdot 8.42}{23.95 \cdot 0.92}=6.87 \mathrm{~A} \\
\eta_{\mathrm{H}} & =(0.9 \div 0.98) \\
\mathrm{U}_{\mathrm{CE} \max } & =\mathrm{U}_{0 \max }=57.46 \mathrm{~V}
\end{aligned}
$$

Selects the transistor VT1 - KT812A:
Table 3. Parameters of the transistor KT812A.

$q=(1.3 \div 2)-$ the coefficient of saturation,

The value of the base currents of the control:

$$
\mathrm{I}_{\mathrm{B} 2,3,4}=\frac{\mathrm{I}_{\mathrm{C} \max } \cdot \mathrm{q}}{\mathrm{h}_{21 \min }}=\frac{6.87 \cdot 1.5}{30}=0.34 \mathrm{~A}
$$

\subsection{The calculation scheme of the pre-amplifier with transformer input}

In (Fig.3) shows a diagram of a pre-amp.

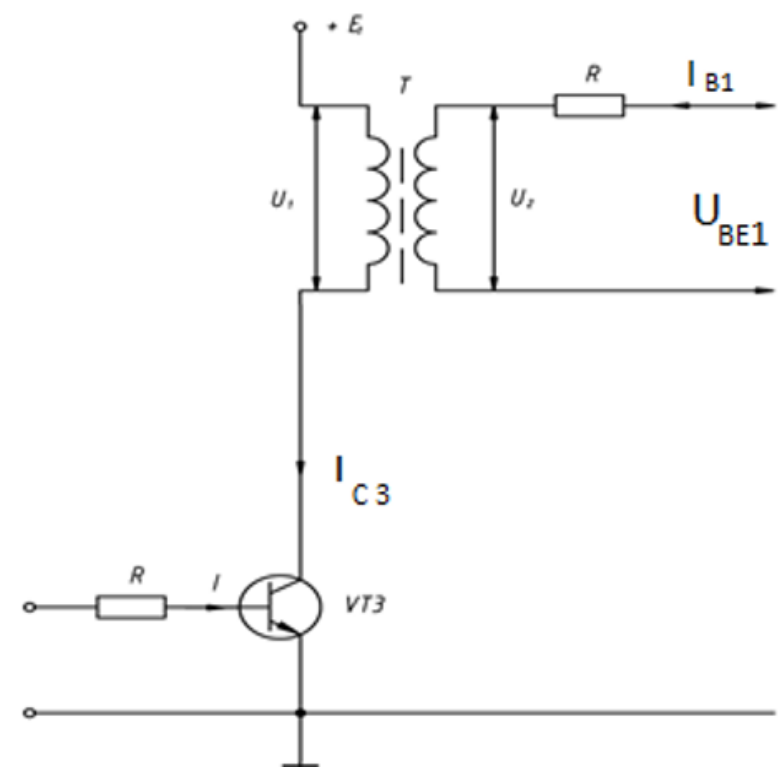

Fig. 3. Diagram of the preamplifier with transformer input.

$$
U_{2}=(3 \div 4) \cdot U_{B E \text { saturation } 1}=3.5 \cdot 2.2=7.7 \mathrm{~V}
$$

Balanced resistance is needed to limit the base current of the power transistor of the Converter (after replacing the transistor) due to the variation of parameters h21e, $U_{B E}$ [5].

Balanced impedance:

$$
\mathrm{R}_{b}=\frac{\mathrm{U}_{2}-\mathrm{U}_{\mathrm{BE} \text { saturation1 }}}{\mathrm{I}_{\mathrm{b} 1}}=\frac{7.7-2.2}{0.27}=20.4 \mathrm{Ohm}
$$

Is selected by row e24: $\mathrm{R}_{\mathrm{B}}=22 \mathrm{kOhm}$.

$$
\mathrm{I}_{\mathrm{C} 3}=\frac{\mathrm{U}_{2} \cdot \mathrm{I}_{2}}{\mathrm{U}_{1} \cdot \eta}=\frac{7.7 \cdot 0.34}{(15-1) \cdot 0.92}=0.2 \mathrm{~A}
$$

$U_{1}=E_{1}-U_{C E \text { saturation }}-$ the amplitude of the voltage of the primary winding of the transformer;

Select transistor VT5-6: 
Table 4. Parameters of the transistor KT630E.

\begin{tabular}{|c|c|c|c|}
\hline Type & $H_{2 l e}$, & $\begin{array}{c}U_{B E \text { saturat }}, \\
\mathrm{V}\end{array}$ & $\begin{array}{c}U_{C E} \\
\text { saturat }, \mathrm{V}\end{array}$ \\
\hline KT630E (n-p-n) & 300 & 0.85 & 0.11 \\
\hline$f_{\text {cutoff },} \mathrm{MHz}$ & $U_{\text {CEmax }}, \mathrm{V}$ & $\begin{array}{c}I_{\text {CEmax }}, \\
\mathrm{A}\end{array}$ & \\
\hline 300 & 60 & 1 & \\
\hline
\end{tabular}

Current control $\mathrm{I}_{\mathrm{B} 3}$ :

$$
\mathrm{I}_{\mathrm{B} 3}=\frac{\mathrm{I}_{\mathrm{C} 3} \cdot \mathrm{q}}{\mathrm{h}_{21}}=\frac{0.2 \cdot 1.5}{300}=1 \mathrm{~mA}
$$

The resistance value $\mathrm{R}$ :

$$
\mathrm{R}=\frac{\mathrm{U}_{\text {out }}^{1}-\mathrm{U}_{\mathrm{BE} \text { saturation }}}{\mathrm{I}_{\mathrm{B} 3}}=\frac{14-0.85}{1 \cdot 10^{-3}}=13 \mathrm{kOhm}
$$

Is selected by row e24: $R=15 \mathrm{kOhm}$.

,$U_{1 \text { out }}$ - voltage logical units on the $\mathrm{I}_{\mathrm{ps}}$ output of the logical element "and" [6,124].

\subsection{The calculation of the comparison circuit and the gain error signal}

In (Fig.4) shows a diagram of the circuit built on the operational amplifier.

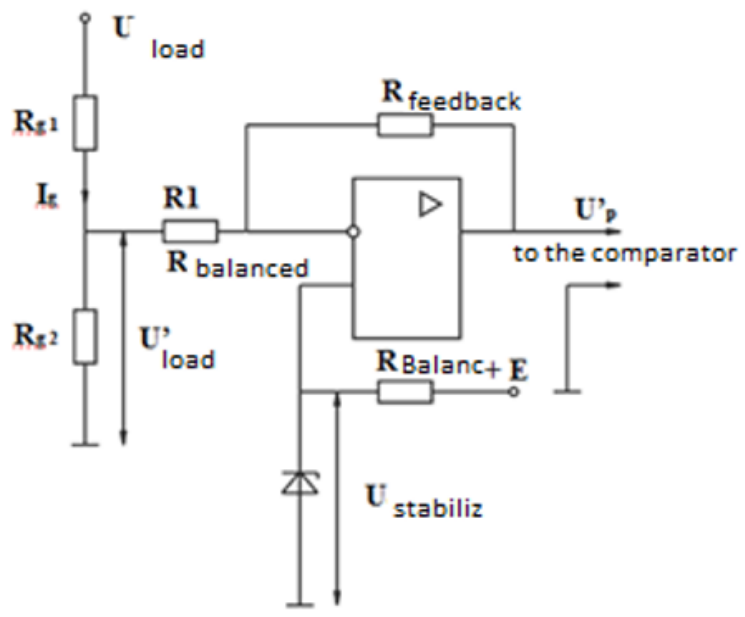

Fig. 4. Comparison Circuit and the gain error signal.

The voltage $U_{\text {st }}$ on the stabilizer is selected from the conditions: $\mathrm{U}_{\text {st }}<\mathrm{U}_{\text {in max }}$, if $\mathrm{U}_{\text {in max }}$ - is the maximum value of the input voltage of the operational amplifier [7,20].

Set the value $\mathrm{U}_{\mathrm{st}}=4.7 \mathrm{~B}$, equating it to the voltage $\mathrm{U}^{\prime}{ }_{\text {load, }}$, t.e. $\mathrm{U}^{\prime}{ }_{\text {load }} \approx \mathrm{U}_{\mathrm{st}}=4.7 \mathrm{~B}$.

The value of the current divider choose: $\mathrm{I}_{\mathrm{d}}=1 \mathrm{~mA}$.

Ballast resistance of reference voltage source:

$$
\mathrm{R}_{\mathrm{b}}=\frac{\mathrm{E}-\mathrm{U}_{\mathrm{st}}}{\mathrm{I}_{\mathrm{st} \min }}=\frac{15-4.7}{3 \cdot 10^{-3}}=3.4 \mathrm{kOhm}
$$

Is selected by row e24: $\mathrm{R}_{\mathrm{b}}=3.9 \mathrm{kOhm}$.

The resistance of the second divider:

$$
\mathrm{R}_{\mathrm{d} 2}=\frac{\mathrm{U}_{\text {load }}^{\prime}}{\mathrm{I}_{\mathrm{d}}}=\frac{4.7}{10^{-3}}=4.7 \mathrm{kOhm}
$$

Is selected by row $24: \mathrm{R}_{\mathrm{d} 2}=4.7 \mathrm{kOhm}$.

The division ratio of the divider:

$$
\mathrm{K}_{\mathrm{d}}=\frac{\mathrm{U}_{\text {load }}^{\prime}}{\mathrm{U}_{\text {load }}}=\frac{4.7}{12}=0.39
$$

The resistance of the first divider:

$\mathrm{R}_{\mathrm{d} 1}=\frac{\mathrm{R}_{\mathrm{d} 2}\left(1-\mathrm{K}_{\mathrm{d}}\right)}{\mathrm{K}_{\mathrm{d}}}=\frac{4.7 \cdot 10^{3} \cdot(0.61)}{0.39}=7.4 \mathrm{kOhm}$

Is selected by row (table) e24: $\mathrm{R}_{\mathrm{d} 1}=8.2 \mathrm{kOhm}$ As the operational amplifier selected chip LM392:

Table 5. Parameters of op-amp LM392.

\begin{tabular}{|c|c|c|c|}
\hline Type & $\begin{array}{c}\text { Type power } \\
\text { supply V, } \mathrm{U}_{\mathrm{ps}}\end{array}$ & $\begin{array}{c}\mathrm{U}_{\text {in }}, \\
\mathrm{V}\end{array}$ & $\mathrm{U}_{\text {out }}, \mathrm{V}$ \\
\hline LM392 & $3-32$ & $-0.3-32$ & $\mathrm{U}_{\mathrm{ps}}-1.5$ \\
\hline Iin, nA & $\mathrm{I}_{\text {out }}, \mathrm{mA}$ & 0 & 0.4 \\
\hline 250 & 6 & $\mathrm{~K}_{\mathrm{u}}$ & $\begin{array}{c}\text { Number of } \\
\text { OG on the } \\
\text { case }\end{array}$ \\
\hline 250 & 20 & $10^{4}$ & OG \\
\hline
\end{tabular}

$$
\mathrm{R}_{\text {feedback }}=\mathrm{K} \cdot \mathrm{R}_{1}=30 \cdot 10 \cdot 10^{3}=300 \mathrm{kOhm}
$$

Is selected by row e24: $\mathrm{R}_{\text {feedback }}=330 \mathrm{kOhm}$. Select the Zener KC139A:

Table 6. Parameters of the Zener diode KC139A.

\begin{tabular}{|c|c|c|}
\hline Model & $\mathrm{I}_{\text {st min }}, \mathrm{mA}$ & Ist max, $\mathrm{mA}$ \\
\hline KC139A & 3 & 70 \\
\hline $\mathrm{U}_{\text {st Rated }}, \mathrm{V}$ & $\mathrm{U}_{\text {st } \max }, \mathrm{V}$ & \multirow{2}{|}{} \\
\hline 3.6 & 4.3 & \\
\hline
\end{tabular}

\subsection{The calculation diagram of the sawtooth generator}

The sawtooth generators find wide application in automation, television, communications technology, measurement technology, power supplies and other applications of electronics [8, 19].

Most often performed with an external control. The duration of the stroke is determined by the duration of the external control pulse of a rectangular shape [9]. If necessary, you can create generators running in sync mode or the oscillatory modex [10].

In the simplest case, when not required high linearity of the working area of the output voltage, they are executed according to the scheme of integrating $\mathrm{RC}$ circuit with the reset of the charge during the return stroke of the saw. The formation of a sawtooth voltage based on the alternation in time of the processes of charge and discharge of the capacitor. The function of the element, creating a circuit to quickly discharge capacitance, performs a transistor in a key mode. Discharge of the capacitor and maintaining the voltage 
close to zero, occurs in the interval tp input signal when the transistor is in saturation (fully open). Linearlyvarying voltage in the interval of the stroke is formed when the transistor is closed (nonconductive state).

In (Fig.5) shows a schematic of the sawtooth generator.

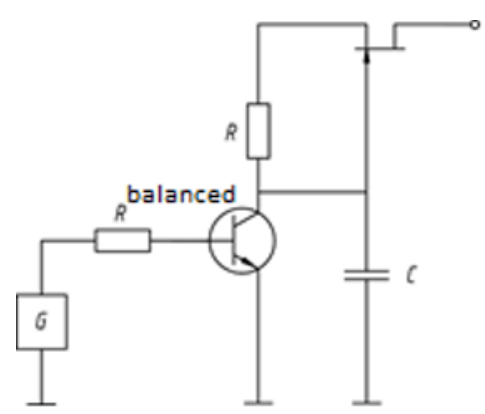

Fig. 5. Oscillator Circuit with a constant current charge.

The pulse period of the sawtooth is calculated according to the formula:

$$
T=\frac{1}{f_{s w}}=\frac{1}{25000}=40 \mu s
$$

The discharge period of the capacitor:

$$
\mathrm{t}_{\mathrm{n}}=0.02 \cdot 40=0.8 \mu \mathrm{s}
$$

The period of charging of the capacitor:

$$
t_{p}=T-\mathrm{t}_{\mathrm{n}}=4-0.8=3.2 \mu \mathrm{s}
$$

The calculation of the capacitance of the capacitor:

$$
\mathrm{C}_{6}=\frac{\mathrm{I}_{\mathrm{c}} \cdot \mathrm{t}_{p}}{\mathrm{U}_{\mathrm{g}}}=\frac{1 \cdot 10^{-3} \cdot 3.2 \cdot 10^{-6}}{3}=1 \mathrm{nF}
$$

Taken on a table e24: $C_{6}=1 n F$

The value of the voltage of the generator is chosen equal to: $\mathrm{U}_{\mathrm{g}}=3 \mathrm{~V}$. $1 m A$

The current value of the capacitor equal to: $\mathrm{I}_{\text {pow.s }}=$

The calculation of the resistance of drain circuit:

$$
\mathrm{R}_{9}=\frac{\mathrm{T}}{\mathrm{c}_{6}}=\frac{4 \cdot 10^{-6}}{1.06 \cdot 10^{-9}}=3.77 \mathrm{kOhm}
$$

Is selected by row e24: $\mathrm{R}_{10}=3.8 \mathrm{kOhm}$. Selects the transistor VT1 - KT315G

\begin{tabular}{|c|c|c|}
\hline Type & $U_{G D \max }, \mathrm{V}$ & $U_{G S \max }, \mathrm{V}$ \\
\hline KP302A & 20 & 10 \\
\hline$U_{D S \max }, \mathrm{V}$ & $I_{\max }, \mu A$ & \\
\hline 20 & 24 & \\
\hline
\end{tabular}

Table 7. Parameters of the transistor KT315G.

\begin{tabular}{|c|c|c|}
\hline Type & $H_{2 l e}$, & $U_{B E . ~ s a t .}, \mathrm{V}$ \\
\hline KT315G & 350 & 1 \\
\hline$U_{\text {CE.sat. }}, \mathrm{V}$ & $U_{\text {kemax }}, \mathrm{V}$ & $I_{\text {kemax }}, \mathrm{A}$ \\
\hline 0.4 & 1 & 0.1 \\
\hline
\end{tabular}

Select the VT2 transistor $-\mathrm{KP} 302 \mathrm{~A}$
Table 8. Parameters of the transistor KP302A.

The base current:

$$
\mathrm{I}_{\mathrm{B}}=\frac{\mathrm{I}_{p s}}{\mathrm{~h}_{21 \max }}=\frac{1 \cdot 10^{-3}}{350}=2.85 \mu \mathrm{A}
$$

Base resistance:

$$
\mathrm{R}_{\mathrm{B}}=\frac{\mathrm{E}-\mathrm{U}_{\mathrm{BE} \mathrm{sat}}}{\mathrm{I}_{\mathrm{B}}}=\frac{15-1}{2.85 \cdot 10^{-6}}=4.9 \mathrm{MOhm}
$$

Is selected by row e24: $\mathrm{R}_{\mathrm{B}}=5.6 \mathrm{MOhm}$.

\section{Results}

As a result, the circuit was simulated and substantially improved in the Multisim program using a separate power source for the control device, which allows controlling the processes occurring both in the network and in the load, regardless of the state of the power unit $(R L=0$ or $R L=\infty)$ [11], which simplifies the task of building a reliable control device.

Using the obtained calculations, it is planned to make a test model of the device. The results of this testing will be described in a future article.

\section{Discussion}

In this section, I want to discuss the merits of a switching voltage regulator relative to a linear regulator. Firstly, it has less energy loss for heating the regulating element, which increases the efficiency of the stabilizer and allows the use of a regulating element of lower power, and a radiator of smaller sizes and weights. You can also note a high efficiency, especially when working in a wide range of input voltages [12, 137]; small dimensions and mass (high specific power); fundamental possibility of galvanic isolation of input and output circuits.

\section{Conclusion}

Today, the scope of application of such devices has decreased in connection with reduction of power supply sources with transformerless input. Nevertheless, the use of switching regulators in a number of cases, it is economically more profitable than any other DC-DC Converter $[13,202]$.

In this paper we discuss the main provisions for the design of power supplies and electronic equipment. When developing a supply of funds was received for construction of circuits of power. Required the estimated coefficient characterizing their performance $[14,47]$. On the technical task [15, 97] was calculated switching voltage regulator, developed in the software Multisim that will be done in further studies. 


\section{References}

[1] V.P. Shuvalov, Telecommunication systems (M.: Radio and communication, 236, 2000)

[2] A.Kh. Shogenov, D.S. Strebkov, Ya.Kh. Shogenov; Ed. Analog, digital and power electronics: textbook (M.: FIZMATLIT, 215, 2017)

[3] E.M. Romash, High-Frequency transistor converters (M.: Radio Communications, 174, 1988).

[4] I. Hamidah, D.F. Ramadhan, The Performance Comparison Between Commercial Automatic Voltage Stabilizer And Programmable Automatic Voltage Stabilizer, Article (2020). ISBN: 18234690

[5] P. Bogomolov, I. Borzdyko, AC Voltage Stabilizer, Article. DOI: 10.30987/conference article_5c19e5e6ca1ba2.66670915 (2018)

[6] E.I. Brezhnev, Effect Transistor apparatus of wide application: reference book (M.: Radio and communication, 278, 1981)

[7] V.V. Durkin, Circuitry of analog electronic devices, Basic concepts, feedbacks, the operation of the amplifying element in the circuit: study guide (Novosibirsk: NSTU Publishing House, 165, 2017)

[8] A.V. Mitrofanov, Pulsed sources of secondary power in consumer audio (M.: Radio Communication, 204, 1987)

[9] R. Maharjan, S. Kamalasadan, Voltage Stability Index for Online Voltage Stability Assessment, Article. DOI: 10.1109/NAPS.2015.7335245 (2020)

[10] M.S. Rawat, S. Vadhera, Voltage Stability Assessment Techniques for Modern Power Systems, Article (2020). ISBN: 9781522585534

[11] V.K. Bityukov, D.S. Simachkov, Sources of secondary power: textbook (M.: InfraEngineering, 2017)

[12] G. Sysoeva, Power supply devices and systems of telecommunications: textbook (VSL, 255, 2002)

[13] A.A. Bass, Secondary power supply Sources with transformerless input (M.: Radio Communication, 368, 1987)

[14] N.V. Sukhanova, Fundamentals of Electronics and Digital Circuitry: textbook (Voronezh: VGUIT, 247, 2017)

[15] E.T. Romancewe. The Development and preparation of design documentation of electronic equipment: a handbook (2nd ed. and additional, M.: Radio and communication, 114, 1989) 